\title{
Corporate Social Responsibility Based on Radial Basis Function Neural Network Evaluation Model of Low-Carbon Circular Economy Coupled Development
}

\author{
Zenghua Gong, ${ }^{1}$ Kaiyi Guo $\mathbb{D}^{2},{ }^{2}$ and Xiaoguang $\mathrm{He}^{3}$ \\ ${ }^{1}$ Datong Municipal Party School, Datong 037009, China \\ ${ }^{2}$ School of Business, Shandong University, Weihai 264209, China \\ ${ }^{3}$ School of Finance, Guangdong University of Finance and Economics, Guangzhou 510260, China \\ Correspondence should be addressed to Kaiyi Guo; guojq@sdu.edu.cn
}

Received 9 February 2021; Revised 25 February 2021; Accepted 3 March 2021; Published 17 March 2021

Academic Editor: Wei Wang

Copyright $(92021$ Zenghua Gong et al. This is an open access article distributed under the Creative Commons Attribution License, which permits unrestricted use, distribution, and reproduction in any medium, provided the original work is properly cited.

Under the background that the development of low-carbon circular economy is the objective requirement for the in-depth implementation of scientific development and the inevitable choice for promoting the sustainable development of economy and society, it is not only the requirement of corporate social responsibility but also the path to realize corporate social responsibility. Enterprises should become the representative and model of social responsibility practice in the development of low-carbon circular economy, in order to promote the fulfilment and development of corporate social responsibility in the whole society. Therefore, it is of great theoretical and practical significance to study the realization of corporate social responsibility in the context of low-carbon circular economy. This paper introduces the connotation of low-carbon circular economy and corporate social responsibility, analyses the reality and theoretical basis of realizing corporate social responsibility in low-carbon circular economy, analyses the interactive relationship between the development of low-carbon circular economy and the realization of corporate social responsibility, and puts forward the construction of enterprise low-carbon operation mechanism. This paper uses the research of corporate social responsibility based on radial basis function neural network to build a low-carbon circular economy. The evaluation model of environment economy coupling development is verified by an example, which provides useful guidance for the evaluation and development of corporate social responsibility.

\section{Introduction}

The rapid change of global climate caused by the extensive use of fossil fuels and the problem of urban environmental pollution caused by haze are becoming increasingly prominent. The long-term high investment, high growth, and extensive development mode lead to a serious departure from the mainstream idea of low-carbon circular economy. With the continuous occurrence of ecological crisis events and the transition of ecological civilization from theoretical cognition to practical stage, corporate social responsibility has become a hot issue of research. In this era of promoting ecological civilization, it is not comprehensive for enterprises to improve their comprehensive competitiveness only through economic means. They should also pay attention to fulfilling the social responsibility of enterprises, especially the requirements of practicing the social responsibility of ecological civilization [1]. While developing the economy, they should also perform the social responsibility in parallel, complement each other, highlight the hard power of enterprises, and reflect the enterprise's competitiveness soft power, to promote the sustainable development of enterprises. However, many enterprises have a weak sense of social responsibility. They still adhere to the traditional highest operating principle cantered on economic interests and ignore the social responsibility that enterprises should bear, which has caused many ecological problems and brought great losses to the country and the people. Based on the requirements of ecological civilization, enterprises not only are users of natural resources and social resources, but 
also should protect these resources, take their own responsibility, and fulfil their obligations for the impact caused by enterprise operation [2].

From the strategic perspective of studying regional lowcarbon circular economy and sustainable development of environmental system, this paper studies the research status at home and abroad and uses sustainable development theory, low-carbon circular economics theory, environmental economics theory, index theory, etc. to study the development of regional low-carbon circular economy and environmental system by qualitative and quantitative analysis and combining theory with practice based on the synergetic theory, the system function, system coupling degree model, and system coupling coordination degree model of low-carbon circular economy and environment that are established.

The rest of this paper is organized as follows: the related work is discussed in Section 2. In Section 3, the radial basis function neural network model is described. Section 4 presents the mechanism of corporate social responsibility on low-carbon circular economy. Section 5 analyses the coupling development evaluation of low-carbon circular economy. Section 6 summarizes the whole paper. The framework of the dissertation is shown in Figure 1.

\section{Related Work}

Corporate social responsibility includes not only the effective management responsibility of providing high-quality and inexpensive products and services for the society and creating profits for investors, but also the social responsibility of employees, consumers, the government, the community, and other stakeholders and the environmental responsibility of environmental protection [3]. Operating according to law is the basic requirement of corporate social responsibility; supporting philanthropy and donating social welfare is the high-level value pursuit of corporate social responsibility. The connotation of environmental responsibility is growing rapidly, and many new responsibility requirements and environmental indicators are emerging, which also increases the difficulty of enterprise environmental management. The low-carbon economic development model embedded in the realization process of corporate social responsibility can effectively improve the realization degree of corporate environmental responsibility and then realize the sustainable development of society [4]. Combining the radial basis function neural network and corporate social responsibility, the low-carbon circular economy coupling development model has been widely concerned and developed in recent years. In recent years, there are many progresses in the research on the coupling development of corporate social responsibility and lowcarbon circular economy [5].

Relevant scholars put forward the construction of corporate social responsibility evaluation index system and set up an evaluation index system for the country, consumers, employees, energy, community, and ecology. Chen Liukin designed an index system including six kinds of evaluation factors, including employee rights protection,

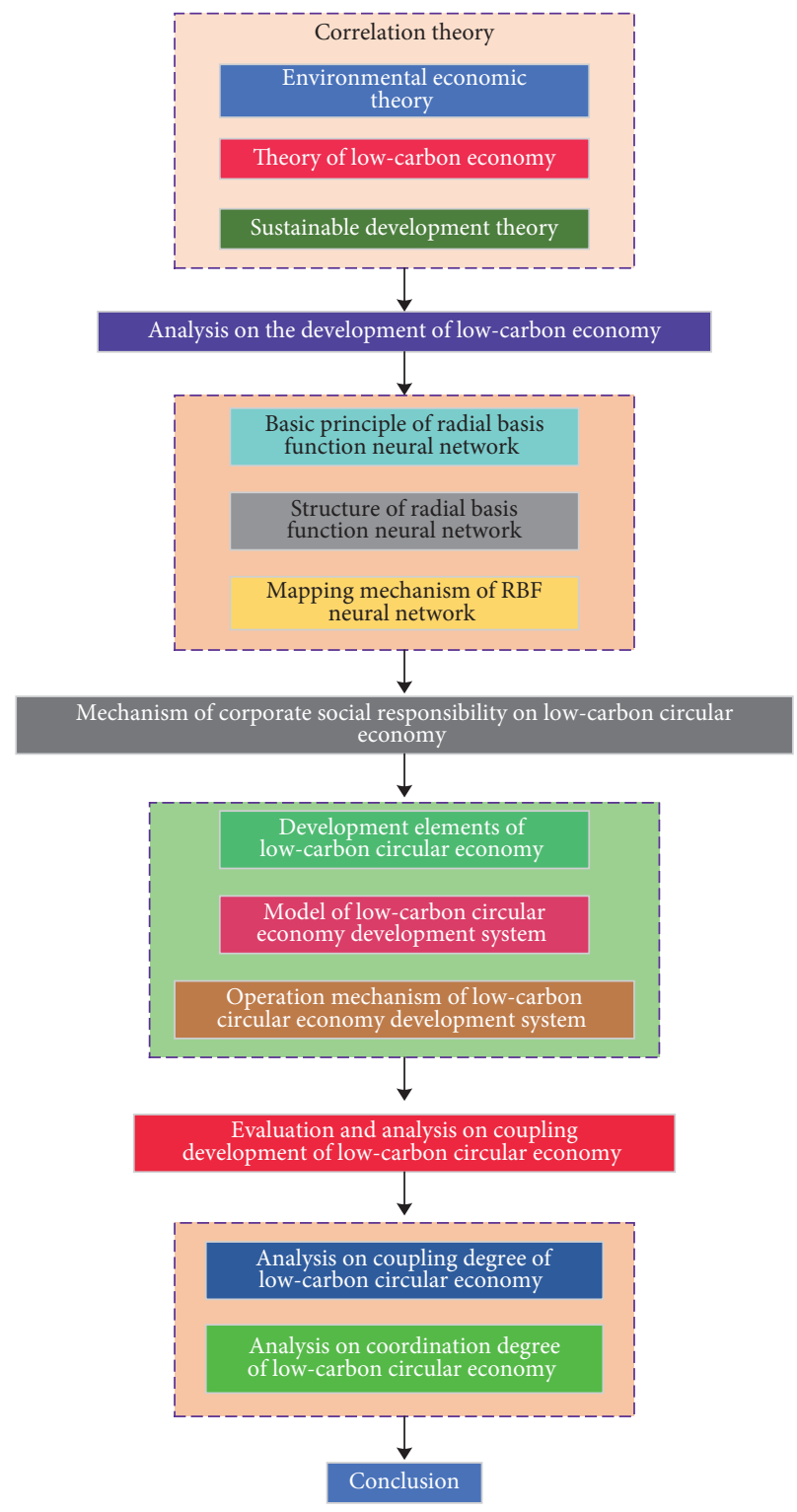

Figure 1: The framework of the dissertation.

environmental protection and sustainable development, enterprise integrity, consumer and creditor rights protection and community relations, social welfare and charity activities, and social responsibility management. Based on the stakeholder theory, this paper constructs the index system of corporate social responsibility; Zhonghu and Zhang Xin construct the index system of power corporate social responsibility evaluation [6], including the four dimensions of power supply, economic laws and regulations, environmental protection and energy conservation, and social harmony. Liu Shenhua and others formulate the seven-dimensional index framework of state-owned enterprise social responsibility evaluation through the research of stateowned enterprises [7]. There are different angles and methods to set up the responsibility index system of enterprises, but most of them are not close to the requirements of the development of low-carbon circular economy. The research status of relevant scholars and the use of sustainable 
development theory, low-carbon economics theory, environmental economics theory, index theory, etc., using qualitative and quantitative analysis, combining theory with practice, study the development and change of regional lowcarbon economy and environmental system. This paper constructs the index system that can represent the regional low-carbon economy and environment system, establishes the low-carbon economy and environment system function and system coupling degree model and system coupling coordination degree model by using the synergetics theory, constructs the evaluation index system of low-carbon economy system and environment system for the emerging energy cities in Tianjin Binhai New Area, and establishes each system by using the software The hierarchical structure model is used to assist the research.

According to the systematic analysis of social contract theory and stakeholder theory, the enterprise can be regarded as a contract of cooperative alliance of stakeholders in each cluster network. The alliance and cooperation relationship between shareholders and enterprises is the embodiment of the contractual relationship, which also includes the contractual relationship between the enterprise and the upstream and downstream enterprises of the supply chain, consumers, government, creditors, social environment, and other stakeholders. These contractual relationships form corresponding responsibilities and rights between enterprises and other stakeholders through formal and informal systems [8]. Enterprises intend to obtain good resources and social environment from the stakeholders, and the premise is to fulfil the corresponding social responsibility to the stakeholders and safeguard their corresponding rights. At the same time stakeholders want to get the corresponding return from the enterprise, they need to provide good resources and social environment for the enterprise [9]. This kind of social contract relationship between enterprises and stakeholders can be regarded as a kind of transaction contract relationship. In a sense, the responsibility of stakeholders can greatly improve the efficiency and quality of the transaction contract [10]. On the contrary, it will affect the social contract relationship between the enterprise and stakeholders and bear the corresponding risks; at the same time, it will suffer the loss to the enterprise when maintaining the reputation of the enterprise, and it will also lead to the corresponding increase of transaction costs [11].

\section{Radial Basis Function Neural Network}

3.1. The Basic Principle of Radial Basis Function Neural Network. Radial basis function neural network is a local approximation network, which can approximate any given nonlinear mapping with any precision. In such a network, the change of samples often only involves the adjustment of a few basis function centres and widths, and the workload of weight modification is relatively small. It is more suitable for dynamic system modelling and pattern classification and is more conducive to the actual operation execution. Radial basis function is a kind of symmetric scalar function along the radial direction, which is generally defined as a monotone function of Euclidean distance between any point $x$ and a centre $C_{i}$ in space. The most used radial basis function is Gaussian kernel function.

$$
\xi\left(x_{i}\right)=\exp \left(-\frac{\sum_{k=1}^{n}\left(x_{k}^{i}-c_{k}^{i}\right)^{2}}{2 \vartheta_{j}^{2}}\right),
$$

where $C_{i}$ is the centre of the kernel function and $\sigma$ is the width parameter of the kernel function, which controls the radial action amplitude of the basis function, i.e., variance, so that it can converge faster and better. Radial basis function network (RBFNN) is a kind of artificial neural network which uses local acceptance domain to perform function mapping. It has the characteristics of optimal approximation and global approximation. The network topology is a forward network composed of a hidden layer and a standard fully connected linear output layer. The hidden layer uses Gaussian radial basis function, while the output layer uses linear activation function. The weight training of $\mathrm{RBF}$ network is carried out layer by layer, the unsupervised weight training is used for the radial base, and the error correction algorithm of supervised training is used for the weight design of output layer. In RBF networks, the output of the basis function from the input layer to the hidden layer is nonlinear, while the output is linear and one-dimensional. In this way, the RBF network can be regarded as a transformation from the original nonlinear separable feature space to another linear separable high-dimensional space [12]. The choice of this transformation will make the original problem linearly separable in the new space and then use a linear unit to solve the problem. The solution of the problem will enter the human visual field, and the transformation from the nonlinear space to the linear state will be realized.

\subsection{Structure of Radial Basis Function Neural Network.} $\mathrm{RBF}$ network is a three-layer feedforward neural network, which has the ability of nonlinear approximation to any function. The first layer is the input layer, and the input data is set as $x=\left(x_{1}, x_{2}, \ldots, x_{n}\right)$, in which each $x_{i}=\left[x_{\gamma 1}\right.$, $\left.x_{\gamma 2}, \ldots, x_{\gamma n}\right]^{T}$ and each $x_{i} \in R, i=1,2, \ldots n$, input layer node only transmits the input signal to the hidden layer, in which the hidden layer has $m$ units, in which the selected basis function is the Gorski function and the output layer is the output layer when the input signal is close to the central range of the basis function, and the hidden node will produce a larger output.

RBF network has three groups of adjustable parameters: hidden layer, function centre, variance, and weight. There are two ways to determine these parameters: one is to get the centre and variance by experience or clustering method. When the centre and variance are selected, because the output is a linear unit, its weight can be directly determined by the least square method; the other is to use the error correction algorithm for supervised learning through training samples to gradually correct the above three parameters; this is a process of continuously moving forward in a circle. Because GDP is a one-dimensional time series, there is only one hidden unit in the output layer, and the topology of RBF neural network is shown in Figure 2. 


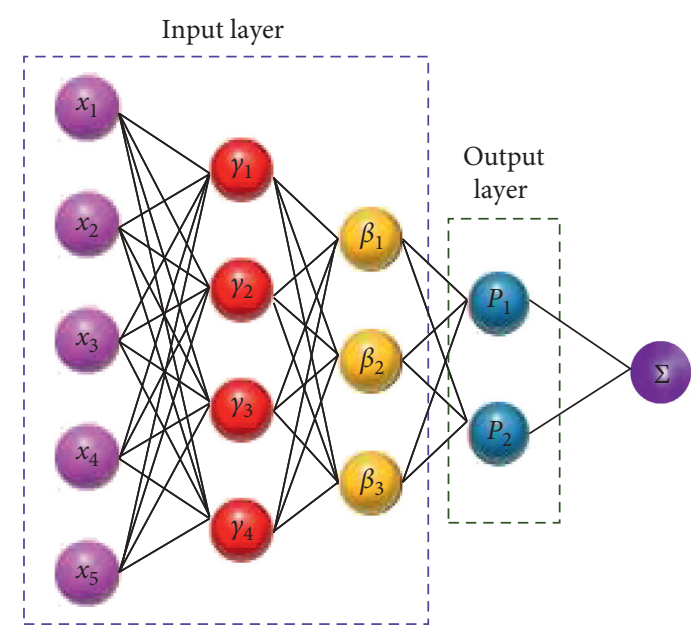

FIgURE 2: Structure of RBF neural network.

3.3. Mapping Mechanism of RBF Neural Network. In BRF network, the hidden layer performs a constant nonlinear transformation, mapping the input space to a new space, where the hidden layer plays an inestimable role. The nonlinear transformation unit is only sensitive to the input near the centre [13]. With the increase of the distance from the centre, the output of the nonlinear transformation unit shrinks quickly to a small value, which shows a local sensitivity; and the speed of reduction is inversely proportional to the width $\sigma$. The three parameters of RBF network do not play the same role in the mapping. The centre and width of the hidden layer represent the pattern of the sample space and the relative position of each centre, which completes the nonlinear mapping. The weight in the output layer is a linear mapping from the hidden layer space to the output space. In the structure of radial basis function network, for the training sample, the index is usually as follows:

$$
\mathfrak{R}=\sum_{j=1}^{n}\left\{\left(y_{i}-\lambda\left(x_{i}\right)\right)+\left(y_{i}-\lambda\left(x_{i-1}\right)\right)+\ldots \ldots+\left(y_{i}-\lambda\left(x_{1}\right)\right)\right\}^{2} .
$$

It can be seen from the above description that index $e$ is a function of centre, width, and responsibility. In a word, the training of RBF network is aimed at a group of samples to minimize $\mathfrak{R}$. Radial basis function network (RBFNN) provides a novel and effective method for learning multilayer feedforward neural networks. Its output is the mapping of sample space to high-dimensional RBFNN. The size of the hidden unit can be fixed according to the change degree of the training sample object and can also be selected adaptively according to the characteristics of the object. When the size of hidden cell and shape parameter of receptive field are fixed, the training and learning of RBF only focus on the training and learning process of the connection weight vector from the hidden layer to the output layer. At this time, the training is based on linear optimization.

3.4. Simulation and Fitting of Radial Basis Function Neural Network. When RBF neural network is used to approximate the noncurrent system, the form of nonlinear function is not very important to the performance of the network, and the number of hidden layer cells determines the process to which the RBF network will fit the training set data. Too many hidden layer neurons will reduce the generalization ability of the network, resulting in overfitting; when there are too few neurons and there is too large error of the training set, the fitting effect is not good. Therefore, the key of RBF network modelling is the selection of hidden layer parameters. (2) Determine the connection weight between hidden layer and output layer.

Figure 3 is the training error curves of BP network and improved radial basis function neural network and traditional radial basis function neural network of function $f(x)$, respectively. The training target error is 0.001 . From the error chart, when BP network is trained to Step 9, the training is up to standard, traditional radial basis function neural network is trained to Step 8, and improved radial basis function neural network only needs training Practice 7 steps, so you can reach the standard. Therefore, the improved RBF neural network has faster convergence speed than BP network and traditional RBF network. The simulation curve of the traditional radial basis function neural network and the improved radial basis function neural network fit well, so the simulation diagram is no longer given here; it represents the sample data fitting curve after network training. After careful observation of their fitting curves, it fits better in the interval $[-0.81]$ and is slightly worse in the interval $[-10.8]$, and it fits better in the whole interval $[-11]$. Among the 21 sampling points, 1 represents the first sampling point and so on. Among the three networks, the approximation error of traditional RBF network is the smallest, the approximation error of improved RBF network at points $1,2,6,9,10,11,12,14,16,19$, and 21 is smaller than that of BP network, and the approximation error at points $3,4,5,7$, $8,13,15,17,18$, and 20 is slightly larger than that of $\mathrm{BP}$ network.

\section{Mechanism of Corporate Social Responsibility on Low-Carbon Circular Economy}

4.1. Development Elements of Low-Carbon Circular Economy. The development system of low-carbon circular economy consists of six aspects: population, resources, environment, management, capital, and technology. These factors and their relationships fundamentally determine the development system of low-carbon circular economy [14]. The relationship between the six elements is a kind of element relationship with low-carbon characteristics around resource allocation. According to the analysis of the basic elements of low-carbon circular economy development system, the components of low-carbon circular economy development system are further divided into low-carbon products, low-carbon human resources, low-carbon technology, low-carbon resources, talent exchange and cooperation, technology exchange and cooperation, low-carbon capital investment, infrastructure, carbon trading intermediary, low-carbon management, market demand 


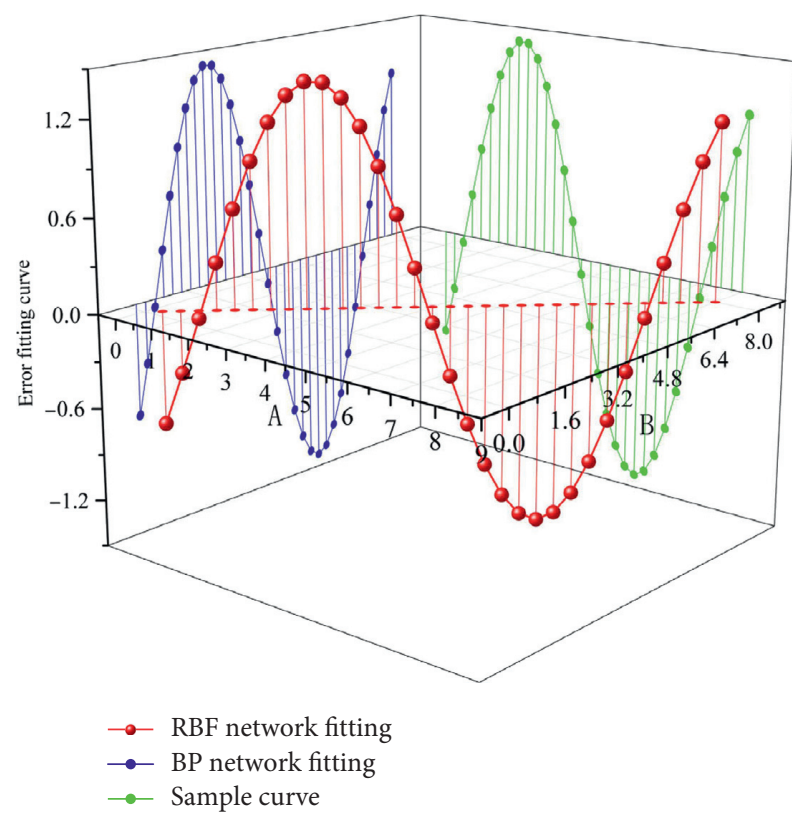

Figure 3: Comparison of training error curves.

environment, capital environment, government administration, economic environment, and low-carbon circular economy as the target layer elements $[15,16]$. According to the relationship between the elements in the development of low-carbon circular economy, the hierarchical relationship between the elements in the development system of lowcarbon circular economy is shown in Figure 4.

In the development system of low-carbon circular economy, the highest level is the development goal of the system, that is, to achieve low-carbon development, which is directly affected by the second level of low-carbon products and mainly achieved by the exchange of low-carbon products. The third levels of low-carbon human resources, low-carbon technology, and low-carbon resources are the direct input factors to produce low-carbon products, through their cooperation to produce low-carbon products. In the fourth level, low-carbon talents exchange and cooperation, low-carbon technology exchange and cooperation, and low-carbon funds are the support and determinants of the quantity and quality of the third level elements; exchange and cooperation are a way to improve the level of low-carbon talents and technology; low-carbon funds ensure the investment of people, finance, and materials [17]. The financial environment, infrastructure, carbon trading intermediary, low-carbon management, and market demand environment in the fifth level can effectively guarantee the fourth level elements from financing, transportation, platform construction, software support, and source power. In the last level, the policy legal environment and economic environment provide the most macrosupport for the whole system by influencing the upperlevel elements.

4.2. Model of Low-Carbon Circular Economy Development System. Combined with the life cycle process of carbon emissions and the flow law of capital, products, and other elements, we can build a complete overall model of lowcarbon circular economy development system, as shown in Figure 4 . We can see that, according to the life cycle process of carbon emissions, the whole system can be divided into four subsystems: energy system, energy saving and emission reduction system, carbon absorption and storage system, and environmental support subsystem. These four systems interact and support each other through the flow of capital, technology, talent, and other elements. Energy saving and emission reduction subsystem is the middle link of the whole low-carbon circular economy development system. Most of the activities of low-carbon development are carried out in the energy saving and emission reduction subsystem. Energy saving and emission reduction mainly come from two aspects: one is from the low-carbon production and the other is from the low-carbon life $[18,19]$. Low-carbon production provides products for low-carbon life, provides products for other departments, contributes tax funds to finance, and absorbs capital, technology, talents, energy, carbon sink, and other input factors from other subsystems. In the aspect of life, funds are transferred to finance through carbon tax, and elements are absorbed from other subsystems, while finance puts funds into low-carbon life and production through the construction of transportation and cities [20].

The carbon absorption and storage subsystem are the final processing link to realize the development of lowcarbon circular economy. The form of carbon storage can be plant carbon sink or carbon sequestration by technical means. The constraint of plant carbon sink is the number of plants, and the constraint of technical sequestration is a major technological breakthrough. This system provides carbon sink, carbon absorption, and storage technology for other subsystems and absorbs energy, capital, technology, talents, equipment, and other input elements from other subsystems [21]. As the guarantee of low-carbon circular economy development system, environmental support subsystem is indispensable. Each subsystem is an open system, exchanging resources and information with the outside world. The good government environment, financial environment, cultural environment, and infrastructure environment build a platform for the cooperation of the other three subsystems and play an important role in the flow of factors [22]. The low-carbon circular economy development system composed of energy structure adjustment subsystem, energy saving and emission reduction subsystem, carbon absorption and storage subsystem, and environmental support subsystem can achieve the goal of promoting the development of regional low-carbon circular economy in addition to the functions of each subsystem. Framework model of low-carbon circular economy development system is shown in Figure 5.

\subsection{Operation Mechanism of Low-Carbon Circular Economy} Development System. The operation of low-carbon development is always around carbon emissions. After the new positioning of low-carbon development, all kinds of elements inside and outside the system, such as people, capital, material, system, and technology, are mainly invested in the 


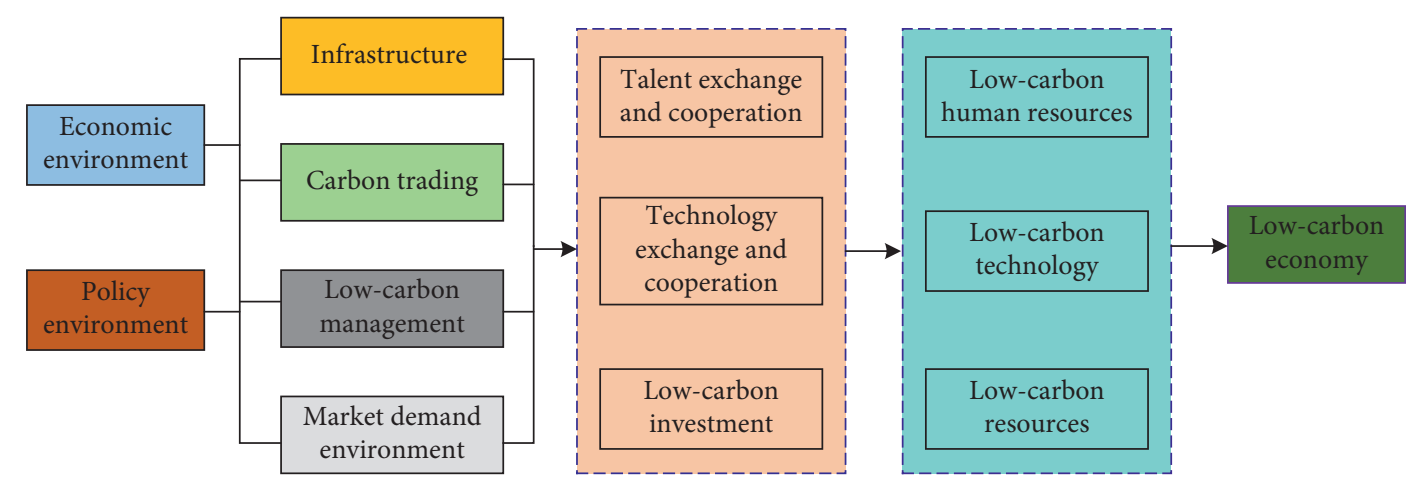

FIgURE 4: Framework model of low-carbon circular economy development system.

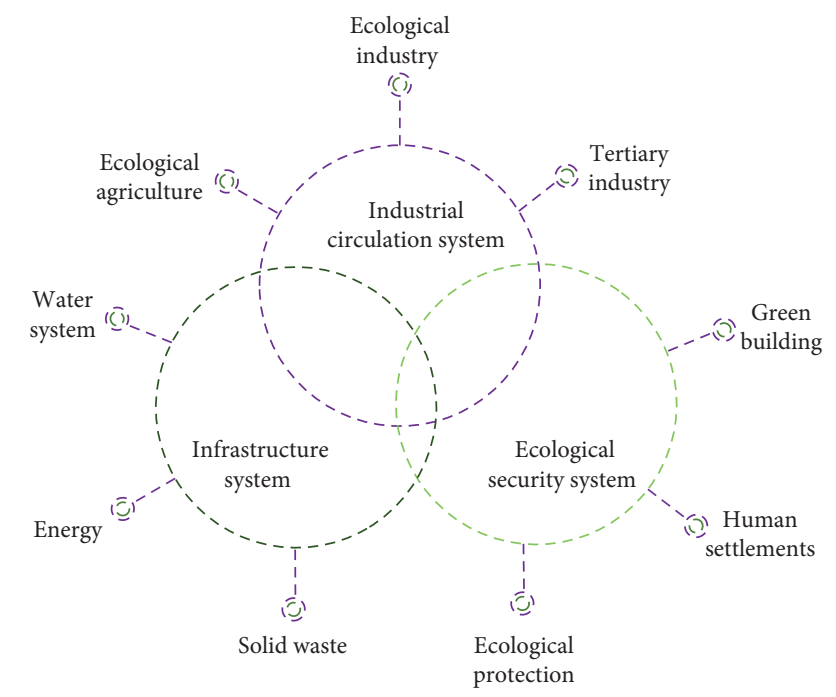

FIGURE 5: Framework model of low-carbon circular economy development system.

cultivation and development of low-carbon system, including the specific business of low-carbon development, forming a new cultivation and development process of lowcarbon development system. The operation of the lowcarbon development system is shown in Figure 6.

Figure 6 shows the mechanism of low-carbon economic development. The operation mechanism of low-carbon development in the form of system is as follows: (1) to establish a special economic development form of lowcarbon development system and to build a perfect lowcarbon development system through this special low-carbon development way and special mechanism and institutional arrangement. (2) Through the development of energy conservation and emission reduction, the industrial value with high energy efficiency will be improved, people's ecological demand will rise, carbon emissions will be reduced, and regional advantages will increase; correspondingly, the scale profit of low-carbon products will increase, and the regional accumulation capacity will increase. (3) The weakening of the original industries with high energy consumption and high carbon emissions overcomes the weakness of traditional industries with high carbon emission rigidity, improves the industrial transformation ability, and increases the factors conducive to low-carbon development. (4) With the development of technology and the rise of energy price, the variety, quality, and quantity of other energy sources in the region will increase, which will increase the scale, reduce the development cost of these energy sources, and improve the overall efficiency of regional energy. (5) Due to the increase of forest and grassland resources, the advantage of low-carbon resources is enhanced, the public welfare benefits of woodland are increased, and the role of ecological base is brought into play, which objectively leads to the increase of ecological investment, to realize the virtuous cycle of woodland [23]. The abovementioned operation of low-carbon development fully reflects the special operation and management requirements of low-carbon development path and resource elements and needs to establish a perfect system to guarantee.

In terms of the triple bottom line theory of corporate social responsibility, the traditional corporate social responsibility mainly reflects the improvement of profits, the dividends from shareholders and taxpayers, the environmental protection, and other social stakeholders [24-27]. From the perspective of corporate social responsibility's own value or mechanism, corporate social responsibility not only creates higher value for stakeholders or external social environment, but also creates corresponding value for the enterprise itself [28]. By combing the relevant analysis of domestic and foreign scholars, when enterprises fulfil their social responsibility, they can enhance the brand reputation, significantly improve the work efficiency of employees, reduce the financing cost of enterprises, and create higher value for enterprises by reducing business risks and optimizing the relationship with the corresponding regulatory authorities $[29,30]$. Corporate social responsibility has brought a win-win mechanism for all stakeholders. Build the mechanism model of manufacturing corporate social responsibility on low-carbon innovation performance.

\section{Experiment and Analysis}

5.1. Analysis on the Development and Change of Low-Carbon Circular Economy System and Environmental System. In this section, combined with theoretical knowledge, by calculating the weights and parameters, we get the score index of each index and each classification of low-carbon circular 


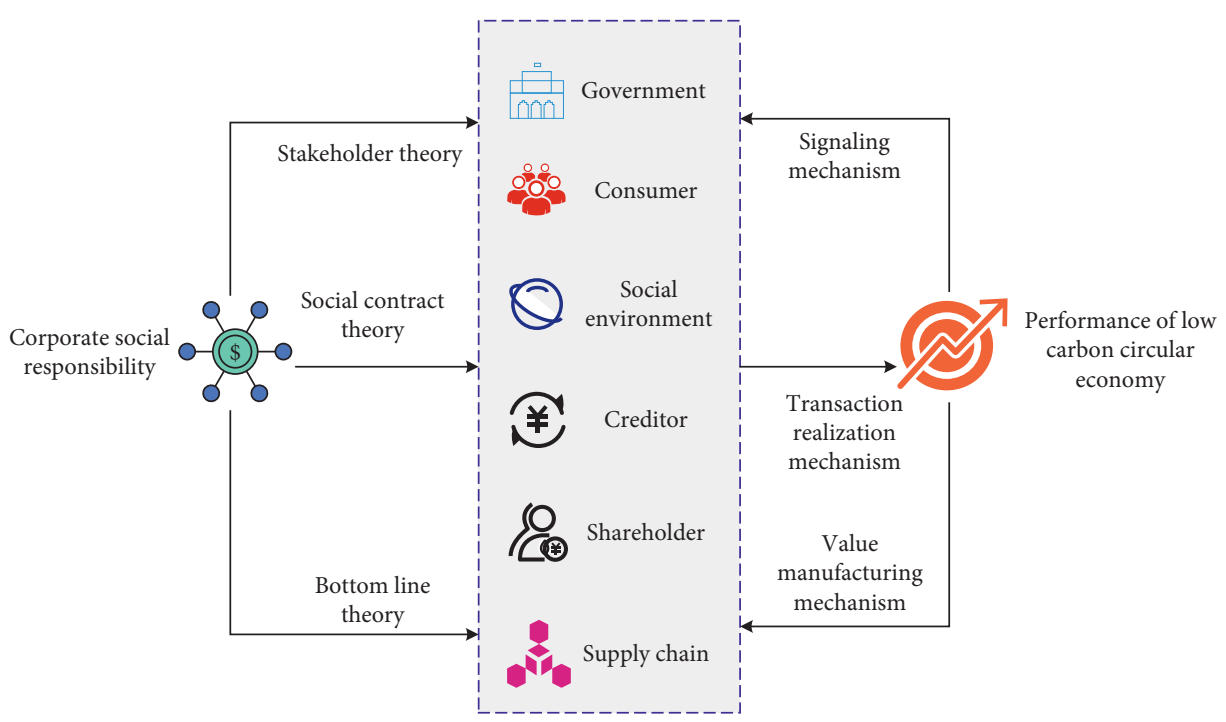

Figure 6: Corporate social responsibility and performance mechanism model of low-carbon circular economy.

economy system and environmental system, as well as the comprehensive score index of low-carbon circular economy system and environmental system. The comprehensive score index of low-carbon circular economy system and environmental system in each year is shown in Figure 7.

It can be seen clearly that the low-carbon circular economy system $f(x)$ of the enterprise is on the rise from 2010 to 2019, which is related to the active opening policy of the area. The development of specific policy support, independent innovation, intensive utilization of resources, integrated construction of functions, and reasonable planning have been achieved. The completion of Zhongli ecocity has also played a huge role in the development of the lowcarbon circular economy of the enterprise promoting role. From 2013 to 2017, the comprehensive index of environmental system was basically between 0.3 and 0.5 . There was a reduction process from 2015 to 2019 since at the beginning of the study period, the development level of low-carbon circular economy of the enterprise is low, and the industrial structure is unreasonable. The economic mode of pollution first and treatment later makes the environmental score decline, and there is a slight decline from 2014 to 2015. This is due to the rapid development of low-carbon circular economy and the improvement speed of environmental quality does not keep up with the development speed of lowcarbon circular economy, so there is a slight decline after 2010, and the environmental development level of the enterprise has reached a new level, showing a positive trend. According to this, we can also get the score of low-carbon circular economy system in Figure 8 and the score of environmental system in Figure 8.

In Figure 8, it can be seen from the figure that the economic development index in the two categories of lowcarbon circular economy system has been greatly improved and consolidated from 2010 to 2019. The economic development index continued to rise, and the low-carbon development index fluctuated slightly in 2004. This is because, at the beginning of the study period, the regional population is small and the low-carbon development level is low. In 2011, the enterprise is an industrial zone dominated by heavy industry, with large carbon emissions and low low-carbon technology level, showing a downward trend; after 2016, it shows a growth trend of alternating flat and rising. As can be seen from Figure 8, the level values of ecoenvironmental variables in the three categories of environmental system show an obvious upward trend. This is due to the clear division of the enterprise, which is divided into eight industrial functional areas and the construction of Sino Singapore ecocity. It has made gratifying achievements in actively developing tourism, increasing green area, paying attention to environmental protection and the development and utilization of new energy, and actively increasing the utilization rate of new energy. The water environment variables and atmospheric environment variables fluctuate greatly, with a downward trend and an upward trend.

\subsection{Analysis on Coupling Degree of Low-Carbon Circular} Economy. We used the economic system evaluation function and environmental system evaluation function, tangent value function, angle conversion, and software production coupling degree calculation. The evolution rate of lowcarbon circular economy system or environmental system can be obtained by deriving the time of low-carbon circular economy system index or environmental system index and dividing the index value of the previous year by the difference between the index values of two adjacent years. The coupling evolution rate is shown in Figure 9.

In this figure, the tangent value of the evolution rate ratio is converted into the angle value by using the coupling degree calculation table. According to the theory and model, the coupling degree of the enterprise's low-carbon circular economy environment system is analysed and evaluated. Due to the substantial improvement of the economic development level, the enterprise has built advantageous industries such as electronic information, automobile 


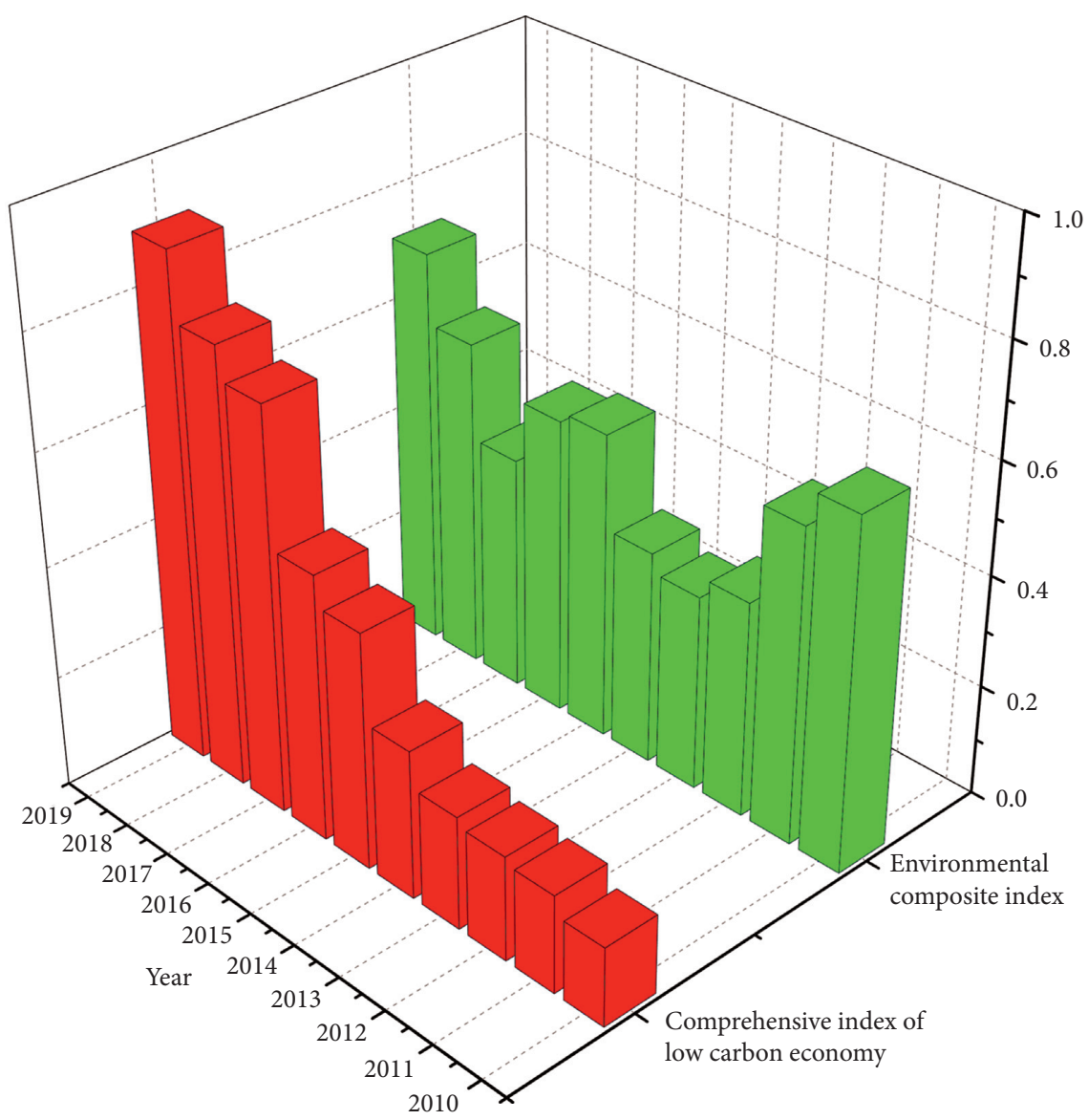

FIgURE 7: Comparison chart of comprehensive score index.

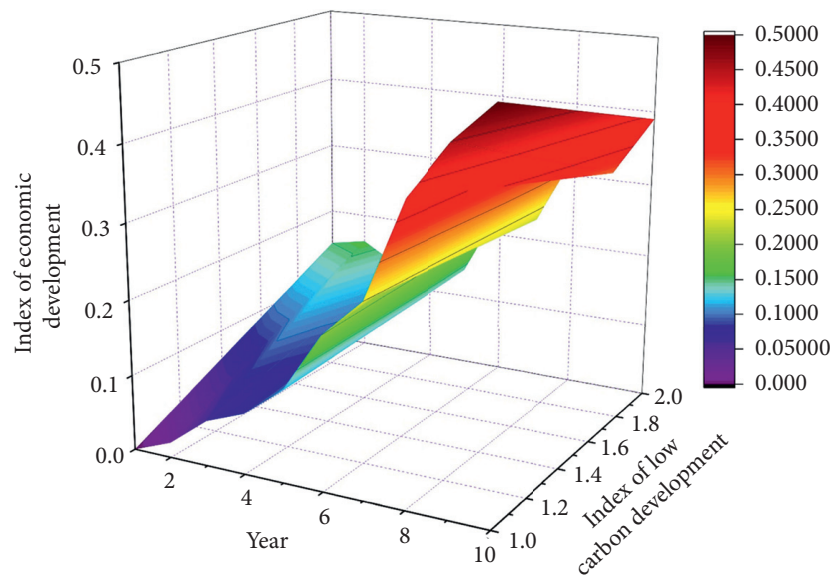

(a)

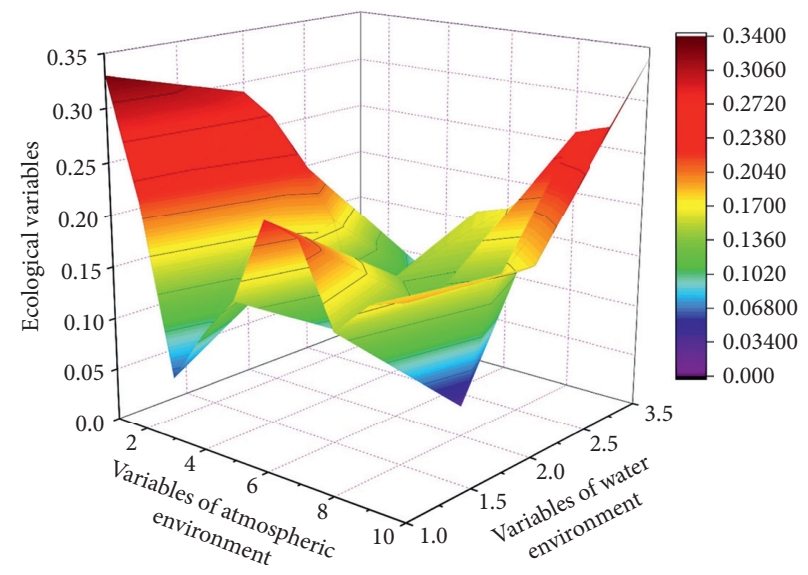

(b)

Figure 8: Comparison of scores of various indicators. (a) Score of low-carbon economy subsystem. (b) Score of environmental subsystems.

manufacturing, and modern metallurgy, and the economic development level is growing rapidly. However, at the same time, the development level of low-carbon circular economy of the enterprise is relatively backward, the low-carbon circular economy is gradually starting, and the central ecocity and major industrial functional areas have not yet been completed. Therefore, the environmental damage is serious, so it is in the primary coupling stage. In the middle of the research period, the coupling degree of low-carbon circular economy and environment of the enterprise has made a qualitative leap and gradually transited from the primary coupling stage to the intermediate coupling stage. During this period, because the government noticed the importance of developing low-carbon circular economy, the 


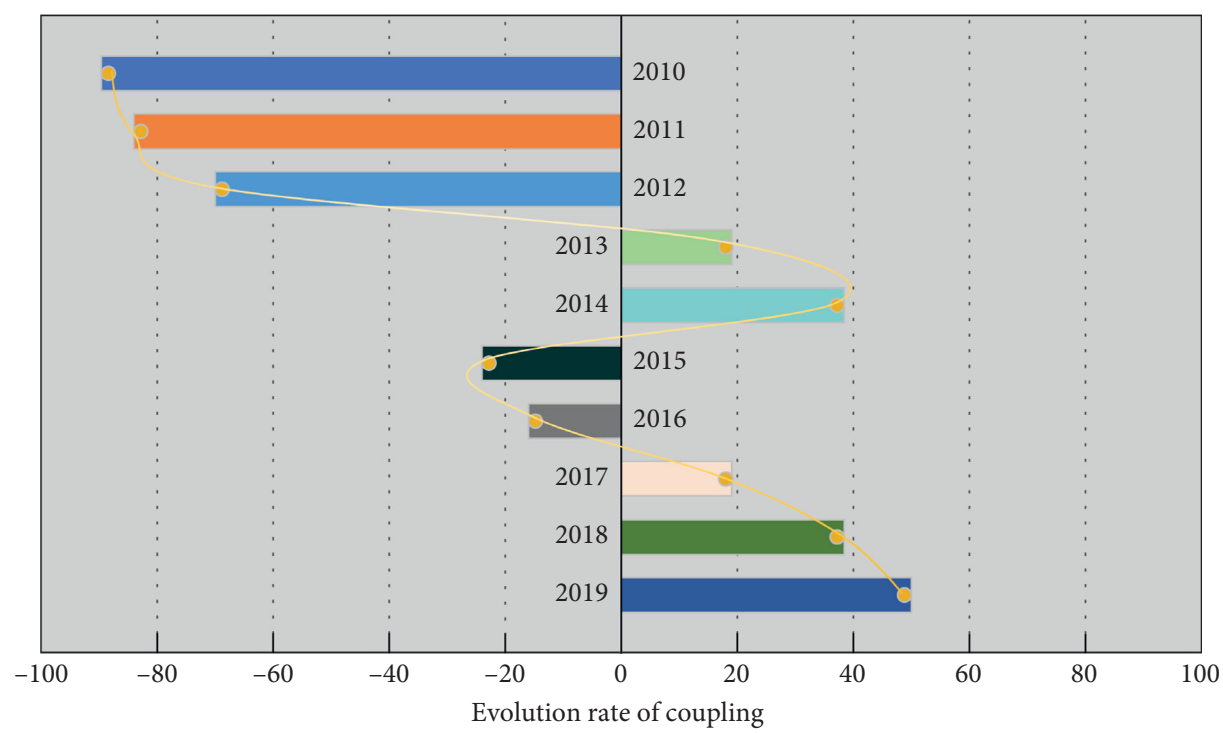

FiguRE 9: Coupling evolution rate of low-carbon circular economy system.

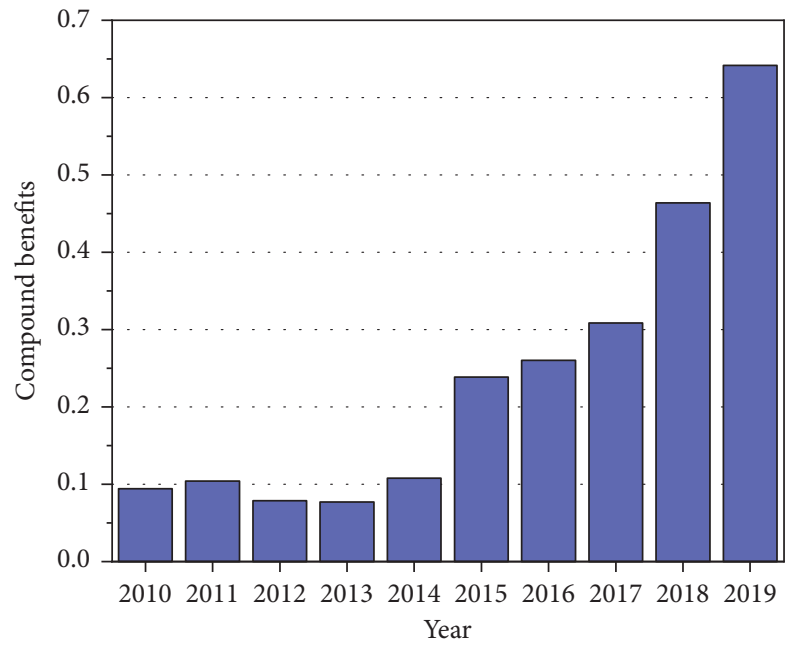

(a)

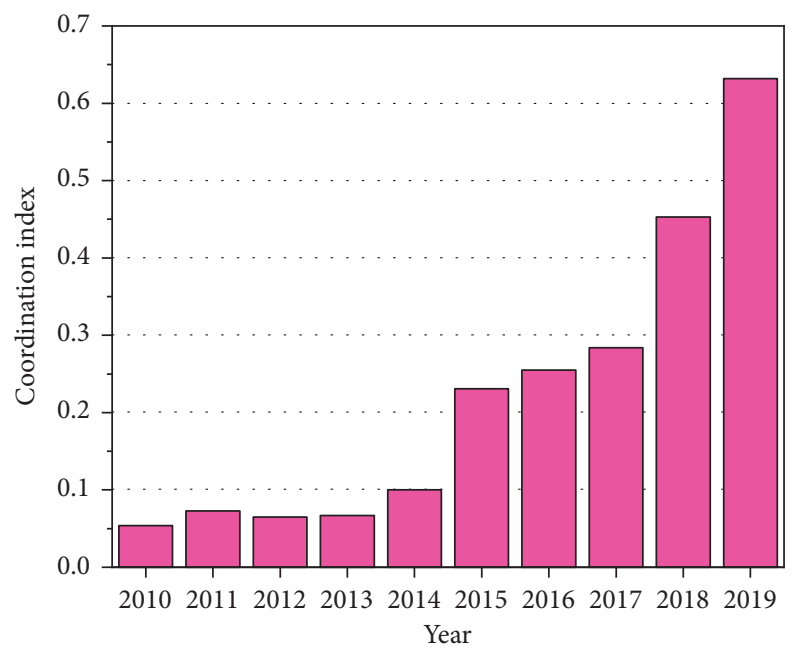

(c)

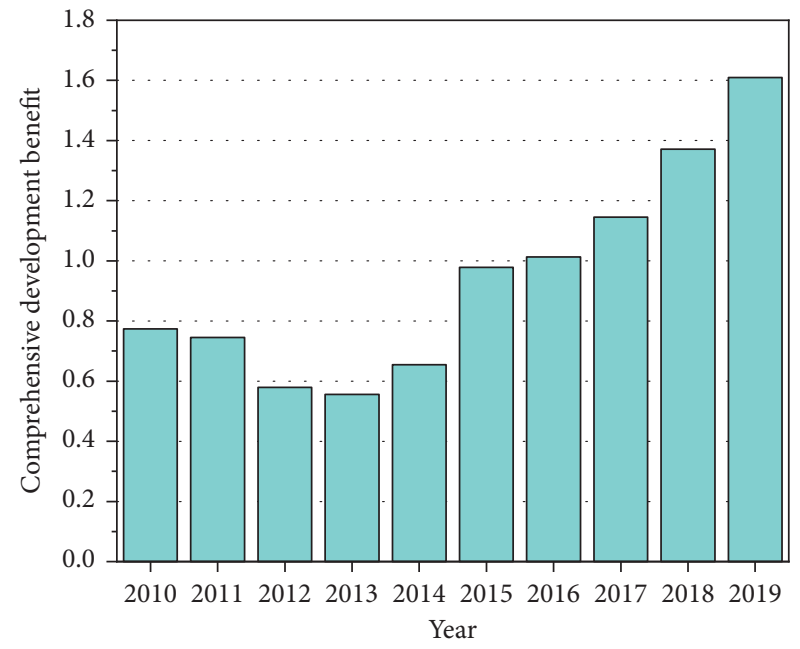

(b)

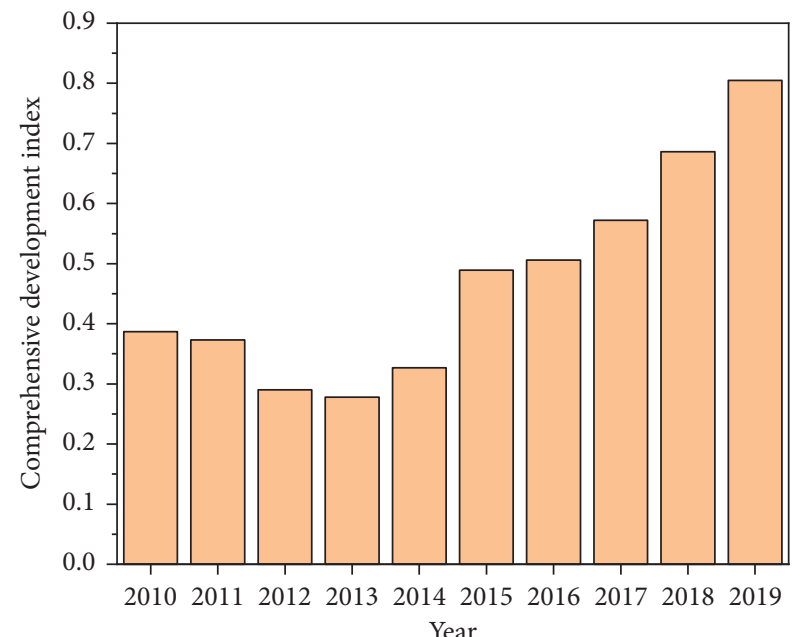

(d)

Figure 10: Analysis on coordination degree of low-carbon circular economy. (a) Compound benefits. (b) Comprehensive development benefit. (c) Coordination index. (d) Comprehensive development index. 
development level of low-carbon circular economy of the enterprise increased rapidly and achieved the goal of project concentration park, industrial cluster development, and resource intensive. The implementation of these effective measures has led to the better development of the enterprise environment and reached the intermediate coupling stage.

\subsection{Analysis on Coordination Degree of Low-Carbon Circular} Economy. Because the system coupling degree cannot fully reflect the overall function and development status of the two systems, it has certain limitations. Therefore, on the basis of the coupling model and coupling coordination model in Chapter 4, the corresponding data of the lowcarbon circular economy and environmental system index system and the analysis data of the enterprise's low-carbon circular economy and environmental system coupling degree, the calculation results are shown in the following Figure 10. The composite benefits of low-carbon circular economy environment system are shown in Figure 10(a), the comprehensive development benefits are shown in Figure 10(b), the comprehensive development index is shown in Figure 10(c), and the coupling coordination degree is shown in Figure 10(d).

From 2010 to 2019, the coordination index of lowcarbon circular economy system and environment of the enterprise showed an overall upward trend. During this period, there were times of decline. In 2016, the low-carbon development index declined. The low-carbon development of the enterprise started with a low level of development, and the environment had been seriously damaged, which led to the decline of the coordination index of low-carbon circular economy and environment system. The development level of low-carbon circular economy rose, the environment improved, and the coordination index of low-carbon circular economy and environment rose. The comprehensive development index of the enterprise's low-carbon circular economy environment system shows an upward trend from 2010 to 2019. Due to the implementation of various policies, the development and utilization of new energy, the prosperity and development of low-carbon circular economy, and the upgrading of industrial structure, the comprehensive development index has been maintained at a certain stable rising stage, which is related to the decline of lowcarbon development index and the decline of environmental system indicators, resulting in the decline of comprehensive development index.

\section{Conclusion}

The development of low-carbon circular economy is not only a challenge but also an opportunity for enterprises. It will directly promote the production, environmental protection, energy conservation, and emission reduction of enterprises. Low-carbon circular economy is not only an effective way to realize corporate social responsibility, but also a new power source to promote the sustainable development of enterprises. Enterprises must recognize the trend of historical development; shoulder the historical mission; take sustainability as the banner, low-carbon development concept as the guidance, low-carbon technology innovation, and system innovation as the driving force; and march towards a new stage of ecological civilization development. This paper introduces the connotation of lowcarbon circular economy and corporate social responsibility, analyses the reality and theoretical basis of realizing corporate social responsibility in low-carbon circular economy, analyses the interactive relationship between the development of low-carbon circular economy and the realization of corporate social responsibility, and puts forward the construction of enterprise low-carbon operation mechanism. This paper uses the research of corporate social responsibility based on radial basis function neural network to build a low-carbon circular economy. The evaluation model of environment economy coupling development is verified by an example, which provides useful guidance for the evaluation and development of corporate social responsibility. However, with the implementation of the sustainable development strategy and the start of the development mode of low-carbon circular economy, there are still some limitations in the strategic perspective of studying the sustainable development of regional low-carbon circular economy and environmental system. In the future research, we will build the index system that can represent the regional low-carbon circular economy and environmental system and establish the function and system of low-carbon circular economy and environmental system coupling degree model and system coupling coordination degree model, in order to provide useful guidance for the evaluation and development of corporate social responsibility, in order to realize the sustainable development of the environment.

\section{Data Availability}

The data used to support the findings of this study are available from the corresponding author upon request.

\section{Conflicts of Interest}

The authors declare that they have no known conflicts of interest or personal relationships that could have appeared to influence the work reported in this paper.

\section{Acknowledgments}

This work was supported by the Project of Shandong Provincial Social Science Office: Research on the Dynamic Evolution and Efficiency Improvement of Financial Support Technology Innovation of Shandong Province (19CJRJ13).

\section{References}

[1] G. D. Zhao, "Policy research on coordinated development of green cycle and low carbon in Henan province," Science of Technology and Industry, vol. 17, no. 5, pp. 11-16, 2017.

[2] G. D. Zhao, "Measuring the efficiency of regional green development in China-a new way to evaluate the efficiency of green development," Journal of Tangshan University, vol. 30, no. 4, pp. 100-108, 2017. 
[3] J. J. Cao, Y. F. Wang, and J. Guo, "Measurement of coupling relationship between economic development efficiency and ecological construction level of key state-owned forest areas," Forestry Economy, vol. 39, no. 8, pp. 77-83, 2017.

[4] Z. S. Wang, N. Zhao, and H. L. Su, "Research on coupling coordination degree of energy economy environment- taking cement industry in Shandong Province as an example," Soft Science, vol. 29, no. 2, pp. 33-36, 2015.

[5] L. Gao, "Identification and optimization of coupling coordination between economic development and ecological environment: a case study of Northeast China," Statistics and Information Forum, vol. 35, no. 1, pp. 74-81, 2020.

[6] Z. H. Huo, Z. Y. Wang, and Y. X. Fan, "Study on comprehensive benefit evaluation and coupling coordinated development of marine fishery in China," Resource Development and Market, vol. 36, no. 5, pp. 486-493, 2020.

[7] N. J. Liu, "Discussion on coupling ways of Tianshui economic development and ecological barrier construction system," Groundwater, vol. 42, no. 4, pp. 216-217, 2020.

[8] M. Y. Wang, Q. Q. Zhang, and W. Q. Shi, "Research on the connotation and development strategy of low carbon circular economy," Journal of Northeast Agricultural University, vol. 15 , no. 5, pp. 46-52, 2017.

[9] J. G. Song and L. H. Wen, "Coupling development of low carbon circular economy and new concept of sustainable development," Journal of Handan University, vol. 23, no. 4, pp. 117-121, 2013.

[10] Y. Jiang, "Construction of coupling development mode and operation mechanism of low carbon circular economy in state owned forest areas," Ecological Economy, vol. 3, pp. 140-142, 2013.

[11] W. A. Du and J. Z. Fang, "The collaborative optimization coupling of finance and real circular economy-also on the paradigm of "leapfrog development" in Hubei," Finance and Accounting Communication, vol. 24, pp. 117-119, 2012.

[12] H. B. Lu, "Research on coupling development of circular economy and low carbon economy," Journal of CPC Central Committee Party School, vol. 16, no. 4, pp. 84-86, 2012.

[13] Y. Jiang and W. Han, "Structural characteristics, and realization approaches of coupling development of low carbon circular economy in state owned forest areas," Economist, vol. 2, pp. 54-56, 2012.

[14] Y. Jiang, "Measurement and analysis of coupling development of low carbon circular economy in state owned forest areas," China Soft Science, vol. 1, pp. 107-115, 2016.

[15] B. Zhou, X. P. Chen, B. Xue, C. Shen, and S. F. Wu, “Theoretical research, and empirical study on coupling development model of low carbon circular economy," Resources and Industry, vol. 12, no. 6, pp. 19-27, 2017.

[16] J. Chen and K. Niu, "Prediction analysis based on radial basis function neural network," China Storage and Transportation, vol. 11, pp. 124-125, 2020.

[17] G. Q. Xu, D. Y. Liu, N. Cao, Y. J. Jia, and J. P. Nan, "Study on slope stability based on improved radial basis function neural network," Microprocessor, vol. 41, no. 5, pp. 21-25, 2020.

[18] C. Chen, F. H. Liao, and C. Zhou, "Thrust compensation algorithm based on improved radial basis function neural network," Special Equipment for Electronic Industry, vol. 49, no. 4, pp. 1-5, 2020.

[19] P. Liu and W. Y. Jia, "RBF radial basis function neural network teaching quality evaluation model based on particle swarm optimization," Modern Computer, vol. 19, pp. 12-15, 2020.
[20] Z. J. Lin, Y. B. Zhang, B. Y. Zhang, S. L. Feng, and Y. J. Shen, "Prediction of platform allowable centre of gravity height based on radial basis function neural network," China Offshore Platform, vol. 35, no. 3, pp. 38-42, 2020.

[21] L. Y. Li, "Research on coordination strategy of three echelon supply chain considering corporate social responsibility," Practice and Understanding of Mathematics, vol. 51, no. 2, pp. 8-19, 2021.

[22] J. Y. Guo and R. F. Xie, "On social responsibility, environmental information quality and enterprise value-based on China's top 300 environmentally sensitive enterprises," Modern Business Industry, vol. 42, no. 6, pp. 1-3, 2021.

[23] L. R. Chen, M. F. Huang, and Z. Y. Sun, "Does the opening of capital market promote enterprises to fulfil their social responsibilities?-based on the moderating effect of product market competition and equity heterogeneity," Journal of Yunnan University of Finance and Economics, vol. 37, no. 2, pp. 54-68, 2021.

[24] S. Du and Z. J. Wang, "Corporate social responsibility disclosure, investment efficiency and enterprise innovation," Journal of Guizhou University of Finance and Economics, vol. 2021, no. 1, pp. 52-62, 2021.

[25] W. Wang, Z. Gong, and J. Ren, "Venue topic model-enhanced joint graph modelling for citation recommendation in scholarly big data," ACM Transactions on Asian and Low-Resource Language Information Processing (TALLIP), vol. 20, no. 1, pp. 1-15, 2020.

[26] W. Wei, Q. Ke, and J. Nowak, "Accurate and fast URL phishing detector: a convolutional neural network approach," Computer Networks, vol. 178, Article ID 107275, 2020.

[27] W. Wang, X. Zhao, Z. Gong, Z. Chen, N. Zhang, and W. Wei, "An attention-based deep learning framework for trip destination prediction of sharing bike," IEEE Transactions on Intelligent Transportation Systems, vol. 10, p. 1, 2020.

[28] I. Kitouni, D. Benmerzoug, and F. Lezzar, "Smart agricultural enterprise system based on integration of internet of things and agent technology," Journal of Organizational and End User Computing, vol. 30, no. 4, pp. 64-82, 2018.

[29] K. G. Srinivasa, B. J. Sowmya, A. Shikhar, R. Utkarsha, and A. Singh, "Data analytics assisted internet of things towards building intelligent healthcare monitoring systems: iot for healthcare," Journal of Organizational and End User Computing, vol. 30, no. 4, pp. 83-103, 2018.

[30] S. K. Biswas, D. Devi, and M. Chakraborty, "A hybrid case based reasoning model for classification in internet of things (IOT) environment," Journal of Organizational and End User Computing, vol. 30, no. 4, pp. 104-122, 2018. 